\title{
Identify and Rank the Barriers to Technology Transfer - Analytic Hierarchy Process
}

\author{
Mansour Forouhar ${ }^{1}$, Mehdi Forouhar ${ }^{2}$, Saeed Gholami ${ }^{3} \&$ Omid Arghish $^{4}$ \\ ${ }^{1}$ MS. Student Industrial Engineering, Islamic Azad University Gachsaran, Iran \\ ${ }^{2}$ Supervisor in Petrochemical Industry, Iran \\ ${ }^{3}$ Lecturer of DBA, Islamic Azad University, Iran \\ ${ }^{4}$ Department Of Industrial Engineering, Gachsaran Branch, Islamic Azad University, Gachsaran, Iran \\ Correspondence: Mansour Forouhar, Student Industrial Engineering, Islamic Azad University Gachsaran, Iran. \\ E-mail: Forouhar_tak@yahoo.com
}

Received: April 27, 2016

doi:10.5539/mas.v10n9p142
Accepted: My 8, 2016

Online Published: June 13, 2016

URL: http://dx.doi.org/10.5539/mas.v10n9p142

\begin{abstract}
Transfer of technology as an inevitable necessity has been interested by scientific directors and executive directors in the past two decades. Obstacles facing this transition in modern countries (developed) in the countries such as Iran is considered significantly. This study is a descriptive survey, and applied in term of purpose. The purpose of this study is to identify and rank the barriers to transfer technology in Iran.

Mentioned study uses literature research and expert opinions gathered through interviews and questionnaires, to identify high-impact barriers and has prioritized the major obstacles to transfer technology through the use of hierarchical analysis. The results show that technical, human, organizational information barriers were the most important barriers to transfer technology in Iran and technical barriers, in the infrastructure; in human barrier, managerial skills, the obstacle information, cost information and ultimately organizational barriers, have created the challenges.
\end{abstract}

Keywords: identify, ranking, barriers, technology transfer, iran, analytic hierarchy

\section{Introduction}

Technology transfer is not a new field of study. Although the emergence of technology transfer words related to 1940 in the United States, however, examples of technology transfer coincided with the emergence of the technology itself is visible. Formal studies technology transfer, research coincided with the publication and distribution technology by social scientists in Europe and quickly to serious research was welcomed as a background. (Rogers, 2001)

This field of research began to grow since 1920 in the United States and spread progressed until late 970. (Rogers, 2001) After a decade of studies on technology transfer stop again focusing on issues of economic sociology, technology and education researchers began a new course of study. (Johnson, 2004)

Given the current state of science and technology in developing countries and the rapid progress in this field must be said that the creation of mankind through research and development of domestic technology simply is not possible and not economic. So for that developing countries to implement policies of their industrial development requires technology transfer from industrial countries. Mechanisms to identify and select final stages of development and new technology is known as technology transfer.

Transfer of technology is a complex and difficult process without the necessary research and studies may lead to wasting time, money and undermining the technology. Several elements are involved in this process. Technology transfer happens in different ways. These methods have been classified in various ways and each has advantages and disadvantages. In this paper we shall try to identify the main barriers to technology transfer documented in research literature and after survey of industry experts and academics are prioritized.

To prioritize the method of AHP, or the Analytical Hierarchy Process is used. This model helps complex phenomenon influenced by many variables in an organized framework. Mentioned model is based on a comparison of paired variables and researchers to compare variables with different measurement units. 


\section{Research Theoretical Foundations}

Technology transfer can be considered as an active process in which technology is transferred from one border to another border. These boundaries can belong to countries, companies and even individuals. In other words, transfer of technology, a process in which the technology somewhere other than the location of its creation, for producing products and also constitutes the basis for the creation of new technologies, is published.

Technology transfer plays an important role in the economic development of modern markets as well as countries develop plays notable role in transitional economies. Technology transfer is a win-win solution for both the transferor and the transferee. However, this process in developing countries (transferee) and extended (the transferor) concerns for both sides in the table:

Table 1. concerns the transfer of technology in developed and developing countries (Source: Li-Hua-2010)

\begin{tabular}{ll}
\hline Developing Countries & Developed Countries \\
\hline $\begin{array}{l}\text { Money paid for the purchase of new technologies and } \\
\text { changing technologies and equipment second hand and }\end{array}$ & $\begin{array}{l}\text { Uncertainty regarding intellectual } \\
\text { property rules in developing } \\
\text { old-fashioned in a day. }\end{array}$ \\
$\begin{array}{l}\text { Technology transfer contracts signed but not secure key } \\
\text { technologies. }\end{array}$ & $\begin{array}{l}\text { Intellectual property infringement } \\
\text { by recipients }\end{array}$ \\
$\begin{array}{l}\text { Plans and programs due to inadequate transmission or } \\
\text { non-transmission technology remain unfinished. }\end{array}$ & \\
\hline
\end{tabular}

Two world of science and industry, have their own languages, including labor conditions, different levels of wages, lack of appropriate incentives for investment in research and development and low demand from industry for research and development (Cogan, 2001) According to Parker (1999) the following barriers to technology transfer are:

$>$ Traditions and values of science (teaching, publications, research with long-term time horizon)

$>$ Priorities and industrial cultures (profit, risk appetite and time horizon short term activities)

Kirkland (1999), classified obstacles into five general categories: Legal barriers, especially intellectual property rights, financial barriers, particularly lack of financial resources, limited human resources (skills); challenges inherent in the relationship between industry and academia, barriers to technological difficulties. Small and medium enterprises suffer from a lack of new technologies. Jones and Jane in 2002 presented four major challenges that will face these firms as follows:

$\checkmark$ New technologies learning: They suffer from a shortage of appropriate information that this is due to the high cost of obtaining relevant information that they provide for those counts.

$\checkmark$ Assess new technology: They don't have the ability to evaluate new technologies for achievements, costs and risks.

$\checkmark \quad$ Successful adoption of new technologies in small and medium enterprises to adapt successful performance management technology with related activities would be taken.

$\checkmark$ Alternative technologies in these firms are less able to obtain external support, cooperation and participation, and therefore obtain appropriate financing for the new technology does not exist.

Anders (2009), presented obstacles to technology transfer in Poland below. Lack of financial resources firm, weakness in science and the lack of proposals derived from this region to the industry, the high cost of technology transfer; limited assistance from the government; legal regulations and bureaucracy, inefficiency information systems; difficulty working with banks and financial institutions; lack of staff and skills; lack of compliance with corporate research and development institutions, lack of appropriate systems to support innovation activities and $\mathrm{R} \& \mathrm{D}$;

Difficulty obtaining external financing of the Company; lack of spirit and a culture of innovation among employees, lack of long-term strategies in the field of science and technology; uncertain of current science and technology policy; poor coordination between government agencies; relative reduction in R \& $\mathrm{D}$ spending in the state budget; very focused policies in the field of financing for research and development activities; limited support applied research budget decisions; too much emphasis on the support of science to innovation, lack of 
innovation and technology transfer policy

Dean introduced barriers to technology transfer in the Persian Gulf countries as follows: (Shortage of human resource, industrial management expertise and skills in the region; bureaucratic constraints, such as rigid and complex rules permit limits; dependence on foreign expertise and lack of attention to women in the workforce, inefficient marketing system and the lack of adequate information about the research capabilities;

Traditional values, customs and religion are relatively small local markets, commercial bank loans limited resistance from local residents against new technologies; industrial projects based on local needs and not on the basis of international competitive advantage; the experience of multinationals in the region; involvement in important industrial countries prohibit the sale of important technologies to countries in the region, the lack of political stability and security in the Persian Gulf (Dean, 2013)

Fahimi (2009) presented obstacles to technology transfer in small and medium enterprises in Malaysia as: (Shortage of investment funds, lack of managerial skills, misinformation about the development of small and medium enterprises, lack of skilled and talented workforce, limited capacity to manage technology and business knowledge, limited access to finance and investment, problems with advice from industry professionals, lack of staff to conduct research into new technologies and innovations).

Yazdani (2011) conducted a study to identify barriers to biotechnology in developing countries impedes the identification of the four categories and each category also introduces the most important factor:

1. barriers related to human resources (some of these countries are not expert bio-technology managers, a shortage of skilled human resources to secure development-related activities in the field of biotechnology, managers who lack economic and commercial aspects of their scientific value, less top managers pay attention to scientific development and the development of their subsidiaries, poor decisions about continuing or stopping projects)

2. Technical barriers: (complex due to the high level of technology and other new technologies may not be possible to compare with the lack of equipment associated with this particular type of technology, lack of industry specific equipment this type of technology being sanctioned Iran and prevent the entry of materials and equipment for the research and producing in the industry

3. information barriers: (optional incorrect country of origin or organization for technology transfer, technology transfer laws in this particular type of technology because of lack of sufficient data, are ambiguous, efforts and activities on technology transfer distinct parallel, inadequate sources of information on the domestic market this particular type of technology, lack of exchange between academia, industry and manufacturing units, weakness and lack of legal entities in the approved contract)

4. organizational barriers (lack of stability in their please and follow-up process is not changed by the next manager, lack of understanding and communication with owners to transfer technology, a lack of appropriate authority for biotechnology experts, lack of ongoing investment in construction projects and research in this context, to achieve the final results, senior management does not support results obtained from biotechnology, rather than organization-based projects, the director-driven.)

Asghari (2013) categorized barriers the transfer of technology in the oil industry in the developing world into two general:

Important economic barriers (lack of tax systems, low savings rates, changes of the exchange rate and the lack of systematic and sustained economic growth)

Related barriers to investment in research and development (low rates of industrial investment in R \& $\mathrm{D}$, was developed manufacturing systems, quality control systems and management weaknesses, lack of necessary technology, weakness in the industrial sector about the existence of scientific and engineering skills to improve production technology and process improvement technology)

From other barriers include the following: (a shortage of skilled workers, lack of assets and funding the refusal of some countries possessing technology, lack of technical training necessary information about the transfer process, lack of planning and engineering activities in the transferee (Segi, 2002; Lin Su, 1991)

\section{Method and Conceptual Model Research}

This research is applied based on objective, and descriptive in term of the nature of the procedure, from research using a questionnaire to collect data and obtain expert opinions in the field of university-industry technology transfer has been discussed. In fact, a questionnaire has been drawn up based on AHP method options. 
Documented in the research literature as barriers for technology transfer is a category diagram. Barriers technology transfer to Iran categories in four general: institutional, human, technical information. Organizational barriers refers such as traditional values prevailing in Iranian organizations, lack of support technology transfer by high-level managers and instability in Iran to follow up the process of change and transition management. Human barriers such as lack of skills, including human resources, lack of managerial skills, lack of spirit and culture of innovation and lack of staff knowledge.

Information barriers related such as communication barriers between industry - academia, cost information and to update them, inefficient marketing system getting adequate information and choosing the wrong country or organization of origin for the transfer of technology is concerned. Technical barriers refers such as financial barriers and support of process of technology transfer, legal obstacles: Including administrative bureaucracy and intellectual property law in Iran, sanctions against Iran, the lack of industrial infrastructure and advanced technologies tailored to their specific and complex technologies in Iran.

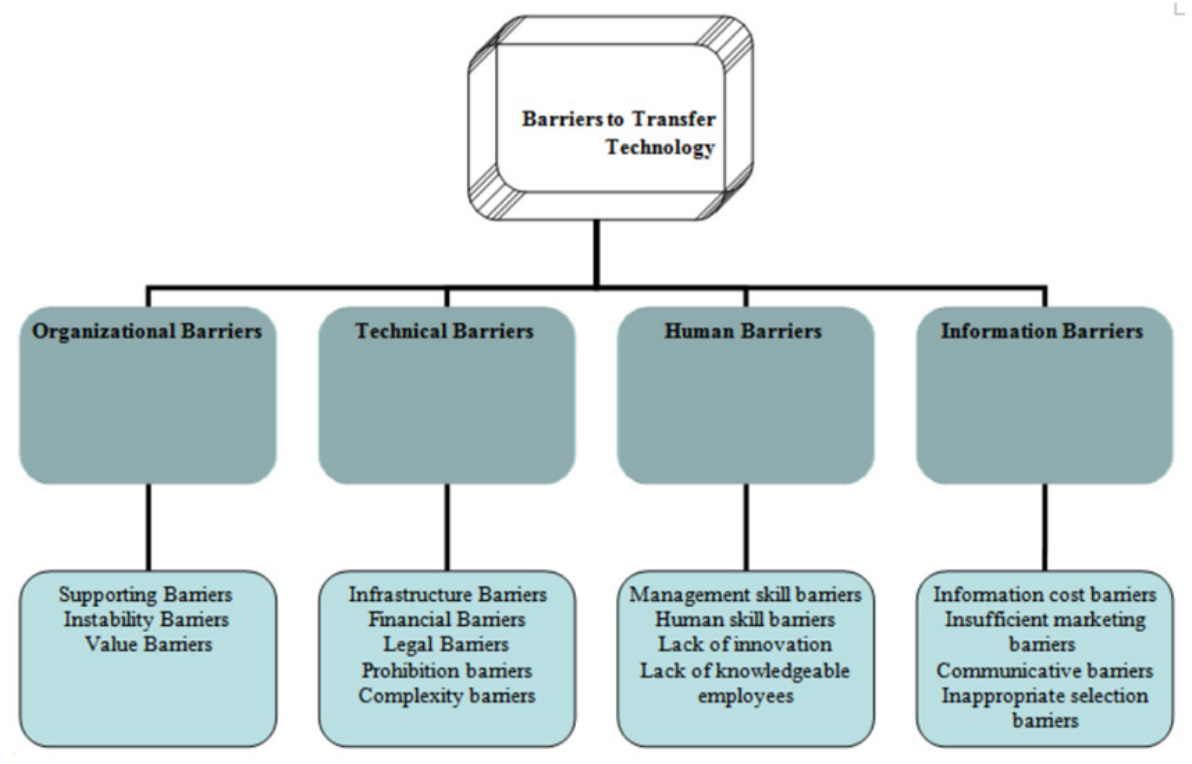

Figure 1. Conceptual model (Source: research findings)

\section{Results and Findings}

In the first part of the barriers for each identified human barriers, organizational, technical and prioritize information, and eventually these obstacles are prioritized. Meanwhile data needed to analyze the data in this study, questionnaires were distributed among a number of industry and academic experts in the field of technology transfer have been collected. In addition, the questionnaire is placed in an appendix.

\subsection{Prioritize Organizational Barriers, Human and Technical Intelligence Using Analytical Hierarchy Process}

Based on the integration experts, matrix geometric mean normalized matrix is presented in Table Two and Three and finally by using AHP, relative weight and prioritize barriers is in accordance to table four. Meanwhile compliance rate for this process 0.004 . Since this value is 0.1 , it is acceptable.

Table 2. Matrix geometric mean human barriers

\begin{tabular}{lllll}
\hline Human barriers & $\begin{array}{l}\text { Human } \\
\text { skill }\end{array}$ & $\begin{array}{l}\text { Management } \\
\text { skill }\end{array}$ & $\begin{array}{l}\text { Lack of innovative } \\
\text { spirit }\end{array}$ & $\begin{array}{l}\text { Lack of knowledgeable } \\
\text { employees }\end{array}$ \\
\hline Human skill & 1 & 0.803 & 4.536 & 6.581 \\
Management skill & 1.246 & 1 & 4.183 & 6.554 \\
$\begin{array}{l}\text { Lack of innovative spirit } \\
\text { Lack of knowledgeable } \\
\text { employees }\end{array}$ & 0.220 & 0.239 & 1 & 1.320 \\
\hline
\end{tabular}


Table 3. Normalized matrix of human barriers

\begin{tabular}{|c|c|c|c|c|c|}
\hline $\begin{array}{l}\text { Human } \\
\text { barriers }\end{array}$ & $\begin{array}{l}\text { Human } \\
\text { skill }\end{array}$ & $\begin{array}{l}\text { Management } \\
\text { skill }\end{array}$ & $\begin{array}{l}\text { Lack of innovative } \\
\text { spirit }\end{array}$ & $\begin{array}{l}\text { Lack of } \\
\text { employees }\end{array}$ & knowledgeable \\
\hline Human skill & 0.382 & 0.366 & 0.433 & 0.426 & \\
\hline $\begin{array}{l}\text { Management } \\
\text { skill }\end{array}$ & 0.476 & 0.456 & 0.399 & 0.424 & \\
\hline $\begin{array}{l}\text { Lack of } \\
\text { innovative } \\
\text { spirit }\end{array}$ & 0.084 & 0.109 & 0.095 & 0.085 & \\
\hline Lack of & & & & & \\
\hline $\begin{array}{l}\text { knowledgeab } \\
\text { le employees }\end{array}$ & 0.058 & 0.070 & 0.072 & 0.065 & \\
\hline
\end{tabular}

Table 4. Matrix ranking human barriers

\begin{tabular}{lll}
\hline Human barriers & Relative priority & Ranking \\
\hline Human skill & 0.402 & 2 \\
Management skill & 0.439 & 1 \\
Lack of innovative spirit & 0.093 & 3 \\
Lack of knowledgeable employees & 0.066 & 4 \\
\hline
\end{tabular}

According to results in Table 4, the main obstacle in the field of management skills and lack of knowledge workers, is the last priority, to prevent human skills and lack the spirit of innovation also placed second and third. Other barriers to briefly summarize the results are shown in Table 5.

Table 5. Matrix ratings technical barriers, informational and organizational

\begin{tabular}{|c|c|c|c|c|c|c|c|c|}
\hline $\begin{array}{l}\text { Technical } \\
\text { barriers }\end{array}$ & $\begin{array}{l}\text { Relative } \\
\text { ranking }\end{array}$ & Ranking & $\begin{array}{l}\text { Organizational } \\
\text { barriers }\end{array}$ & $\begin{array}{l}\text { Relative } \\
\text { ranking }\end{array}$ & Ranking & $\begin{array}{l}\text { Information } \\
\text { barrier }\end{array}$ & $\begin{array}{l}\text { Relative } \\
\text { ranking }\end{array}$ & Ranking \\
\hline $\begin{array}{l}\text { Infrastructure } \\
\text { barriers }\end{array}$ & 0.421 & 1 & Value barrier & 0.126 & 2 & $\begin{array}{l}\text { Information } \\
\text { cost }\end{array}$ & 0.487 & 1 \\
\hline $\begin{array}{l}\text { Financial } \\
\text { barriers }\end{array}$ & 0.238 & 2 & $\begin{array}{l}\text { Supporting } \\
\text { barrier }\end{array}$ & 0.774 & 1 & $\begin{array}{l}\text { Insufficient } \\
\text { marketing }\end{array}$ & 0.305 & 2 \\
\hline Legal barriers & 0.127 & 3 & $\begin{array}{l}\text { Instability } \\
\text { barrier }\end{array}$ & 0.101 & 3 & $\begin{array}{l}\text { Communicat } \\
\text { ive barriers }\end{array}$ & 0.115 & 3 \\
\hline Prohibition & 0.122 & 4 & & & & $\begin{array}{l}\text { Inappropriat } \\
\text { e selection }\end{array}$ & 0.093 & 4 \\
\hline $\begin{array}{l}\text { Complexity of } \\
\text { technology }\end{array}$ & 0.091 & 5 & & & & & & \\
\hline
\end{tabular}

Meanwhile rate of adaptation to technical barriers, organizational and informational respectively is $0.011,0.016$ and 0.004 , which is indicative of the acceptability of comparisons.

\subsection{Prioritize Barriers Technology Transfer Using Analytical Hierarchy Process}

Based on the integration experts, matrix geometric mean of the normalized matrix barriers technology transfer is presented in Table 6 and 7 and finally, using AHP, relative weight and prioritize barriers is as shown in Table 8 . Meanwhile compliance rate for this process is 0.067 . Since this value is 0.1 , it is acceptable.

Table 6. Matrix geometric mean human barriers

\begin{tabular}{lllll}
\hline $\begin{array}{l}\text { Technology transfer } \\
\text { barrier }\end{array}$ & Human barrier & $\begin{array}{l}\text { Technical } \\
\text { barrier }\end{array}$ & $\begin{array}{l}\text { Organizational } \\
\text { barrier }\end{array}$ & $\begin{array}{l}\text { Information } \\
\text { barrier }\end{array}$ \\
\hline Human barrier & 1 & 0.158 & 4.743 & 1.783 \\
Technical barrier & 6.346 & 1 & 7.789 & 6.581 \\
Organizational barrier & 0.211 & 0.128 & 1 & 0.803 \\
\hline
\end{tabular}




\begin{tabular}{lllll}
\hline Information barrier & 0.561 & 0.152 & 1.246 & 1 \\
\hline
\end{tabular}

Table 7. Normalized matrix is human barriers

\begin{tabular}{lllll}
\hline $\begin{array}{l}\text { Technology transfer } \\
\text { barrier }\end{array}$ & Human barrier & Technical barrier & Organizational barrier & Information barrier \\
\hline Human barrier & 0.123 & 0.110 & 0.321 & 0.175 \\
Technical barrier & 0.782 & 0.695 & 0.527 & 0.647 \\
$\begin{array}{l}\text { Organizational } \\
\text { barrier }\end{array}$ & 0.026 & 0.089 & 0.068 & 0.079 \\
Information barrier & 0.069 & 0.106 & 0.084 & 0.098 \\
\hline
\end{tabular}

Table 8. Matrix ranking human barriers

\begin{tabular}{lll}
\hline Technology transfer barrier & Relative priority & Ranking \\
\hline Human barrier & 0.182 & 2 \\
Technical barrier & 0.663 & 1 \\
Organizational barrier & 0.065 & 4 \\
Information barrier & 0.089 & 3 \\
\hline
\end{tabular}

According results in Table 8, the main technical obstacle preventing the transfer of technology and organizational barriers, is the last priority, human and information barriers also are ranked second and third. Research results in Figure 2 below.

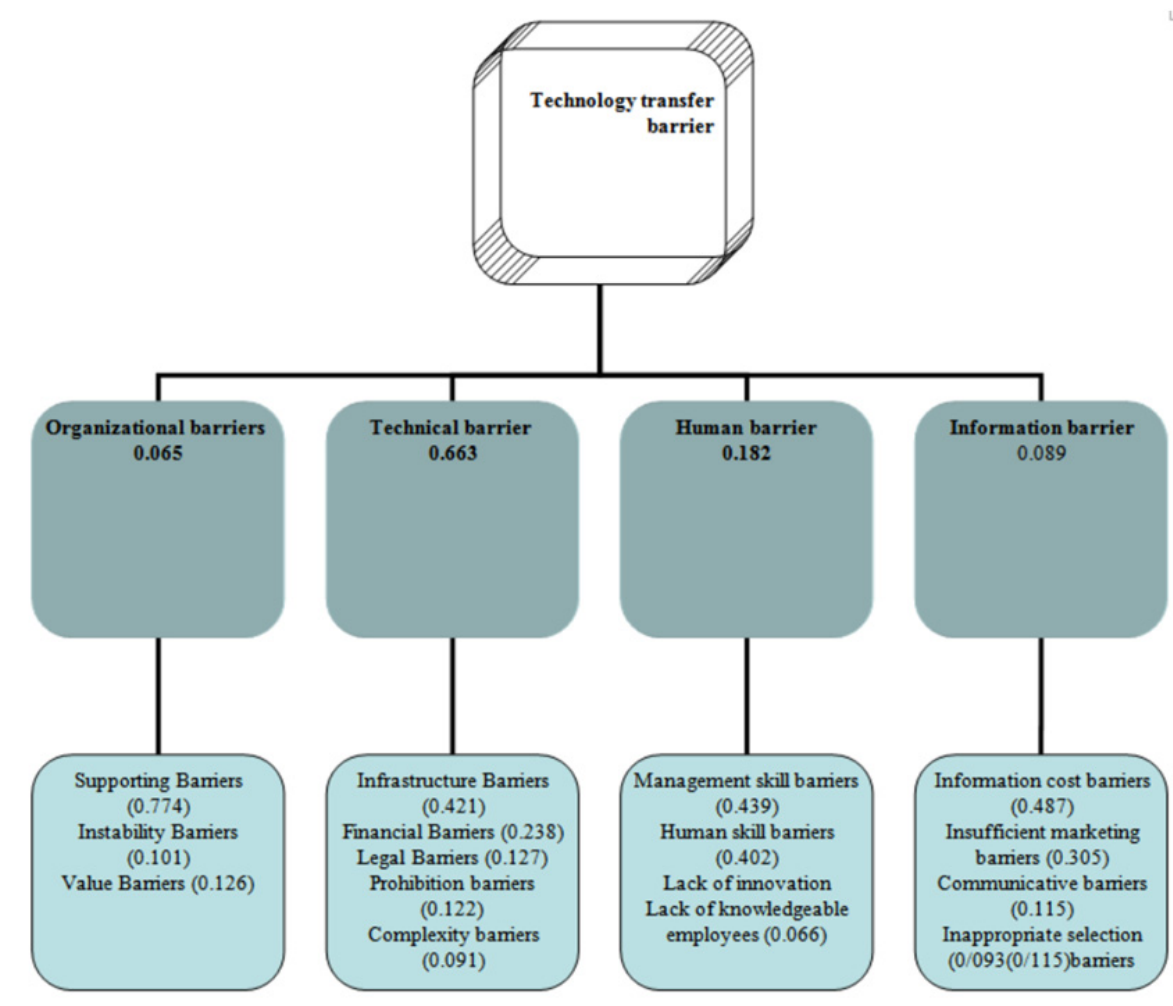

Figure 2. Research results

\section{Discussion and Conclusion}

Technology transfer is key issue in promoting a country's level of technology. This category is considered difficult and complex process without the need to not only useful, but may, in addition to wasting money and 
time, lead to a weakening of national technology. On the other hand, due to different levels of scientific progress and technological communities, technology transfer is an inevitable necessity. Appropriate technology transfer mechanisms to institutionalize a mechanism and technology development in the industry will have to keep global markets.

The overall objective of this paper is as described in the text, is identify and prioritize barriers technology transfer to Iran using the experiences of developing countries. For this first comprehensive study of the literature using factors based on four general categories (human, informational, organizational and technical) identified and for each category, will identify the main obstacles associated with it. Then questionnaire was developed and among a handful of experts in the field of industry and university technology transfer nobles were completely distributed and the results were analyzed using the techniques of the Analytic Hierarchy.

Based on the results of the analysis of the barriers, technical barriers as the main obstacle was announced that this category includes barriers (infrastructure, financial, legal, sanctions and complexity of technology) industry. Infrastructure barriers were identified as the main obstacle to technology transfer due to lack of infrastructure in Iran, it is not far-fetched. After technical factors, human factors priority to the allocation of the second.

Human factors on a priority basis include:

1. Managerial skills,

2. Human skills,

3. Lack of innovative spirit

4. Lack of knowledge workers.

In the third priority category received information that these factors were:

1. Cost information prevented,

2. Marketing prevent inefficient,

3. Communication barrier

4. Prevent adverse selection are transferring technology.

Finally, organizational factors were the last priority in this category, barriers were:

\section{Protective barrier}

2. Organizational values stiff barrier to former technologies and finally,

3. Instability hinders management.

The results of this study barriers technology transfer in general is studied in Iran, these results can be as a prelude to the identification of technology transfer in specific industries. It is recommended that in future studies of this research to identify barriers technology transfer in industries such as oil and gas, communications, etc. should be used.

As was observed in the graph, conceptual model, considered barriers independently, therefore, in future studies could also consider the relationship between these factors and more detailed version of the model presented in this study.

\section{References}

Andrzej, J. (2009). Barriers for technology transfer: the case of a country in transition”, Journal of Technology Management in China, 4(2), 119-131.

Burhanuddin, M. A., Fahmi, A., \& Azizah, V. (2009). Barriers and Challenges for Technology Transfer in Malaysian Small and Medium Industries, International Conference on Information Management and Engineering. 978-0-7695-3595-1/09 \$25.00 (c) 2009 IEEE.

Cogan, J. (2001). Industry-science relationships", background paper, Innovation Trend Chart Workshop, Brussels.

Dean, S. E., Ahmed, S., \& Abou, Z. (2013). Patterns of technology transfer among the Arab Gulf States: opportunities and challenges.

Johnson, S. D., Faye, G. E., \& Hicks, D. (2004), Expanding the Content Base of Technology Education.

Jones, M., \& Jain, R. (2002). Technology transfer for SMEs: challenges and barriers. International Journal of Technology Transfer and Commercialisation, 1(2). 
Kim, L. (1991). Pros and Cons of International Technology Transfer: A Developing Country View. In Tami Agmon and Mary Ann von Glinow (Eds.), Technology Transfer in International Business, Oxford University Press: New York, 223-239.

Kirkland, J. (1999). Introduction. in Kirkland, J. (Ed.), Barriers to International Technology Transfer, Kluwer Academic Publishers, Dordrecht.

Li-Hua, R. (2010). Opportunities and Challenges in International Technology Transfer. International Technology Transfer Workshop, Ningbo, China, 15 October. http://www.ipr2.org/storage/RLH_NB-EN899.pdf

Mahdi, A., \& Mohammad, A. R. (2013), Technology transfer in oil industry, significance and challenges, nternational Conference on Leadership, Technology and Innovation Management. Procedia- Socialand Behavioral Sciences, 75(2013), 264-271.

Parker, L. E. (1999). Adoption and adaptation of technology transfer mechanisms between nations. In Kirkland, J. (Ed.), Barriers to International Technology Transfer, Kluwer Academic Publishers, Dordrecht.

Rogers, D. M .A. (2001). Knowledge innovation system: The common language. Journal of Technology Studies, $19(2), 2-8$.

Rogers, E. M. (2001). Diffusion of innovation. (4th Ed.). New York: Free press.

Saggi, K. (2002). Trade, Foreign Direct Investment, and International Technology Transfer: A Survey, World Bank Research Observer.

Yazdani, K., Rashvanlouei, K. Y., \& Ismail, K. (2011). Ranking of technology transfer barriers in developing countries; case study of Iran's biotechnology industry IEEE International Conference on Industrial Engineering and Engineering Management (IEEM), 978-1-4577-0739-1/11/\$26.00 @2011 IEEE.

\section{Appendix}

\section{Dear Respondent}

Hello

Sincerely, your questionnaire before the study to "identify and rank the barriers technology transfer to Iran using the experiences of developing countries and the Analytic Hierarchy Process" has been designed. No doubt your precious attention and comments contributed to the findings of our research will be in the correct orientation. It is further appreciated that, given the practical experiences and others, insufficient attention has been given in response to questions posed above. It is obvious that the information contained in this questionnaire is completely confidential. In this study will help us do that, sincerely thanked and appreciated.

We wish new successes

* Instructions Questionnaire (Please be sure to complete the following study.)

\section{Introduction Barriers}

In this questionnaire categories barriers to technology transfer to Iran four general: institutional, human, technical information. Organizational barriers refers such as traditional values prevailing in Iranian organizations, non-support technology transfer by high-level managers and instability in Iran to follow up the process of change and transition management. Human barriers such as lack of skills, including human resources, lack of managerial skills, lack of spirit and culture of innovation and instability management.

Information barriers related such as communication barriers between industry - university cost information and to update them, inefficient marketing system getting adequate information and choosing the wrong country or organization of origin for the transfer of technology is concerned. Technical barriers such as financial barriers and support of the process of technology transfer, legal obstacles: Including administrative bureaucracy and intellectual property law in Iran, sanctions against Iran, the lack of industrial infrastructure and advanced technologies tailored to their specific and complex in Iran refers technologies.

\section{Responding Method and Rating To Tables}

Dear respondent please answer the questions in a manner following example. Suppose that you want to both human and technical obstacles, barriers to technology transfer, compare. In this case operation is as follows. 


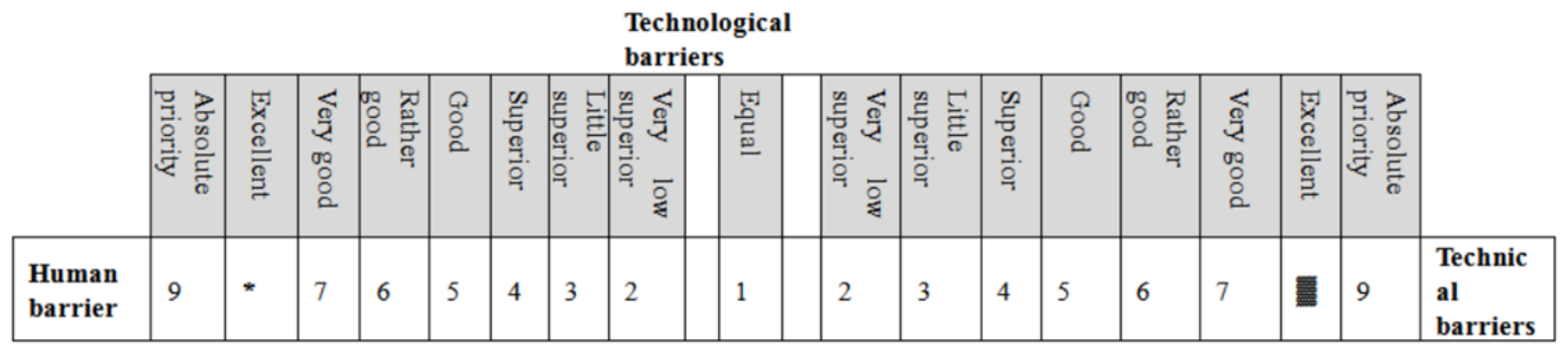

Marked * indicates prevent more human than technical barrier, but symbols important than human barrier. Make sure that you only have to check a house.

\section{General Features}

\begin{tabular}{lllll}
\hline Women $\square$ & & Men $\square$ & Gender \\
\hline 50 years and older $\square$ & 40 to 50 years old $\square$ & 30 to 40 years old $\square$ & Lower 30 years old & Age : \\
Ph.D. and upper $\square$ & MA $\square$ & & BA $\square$ & Education : \\
Academic $\square$ & Industry $\square$ & Skill & & \\
\hline
\end{tabular}

\section{* Specialized Questions}

\section{Paired comparisons of criteria}

1. In line with identify barriers to technology transfer, check technical barriers, human, organizational and compare the information.

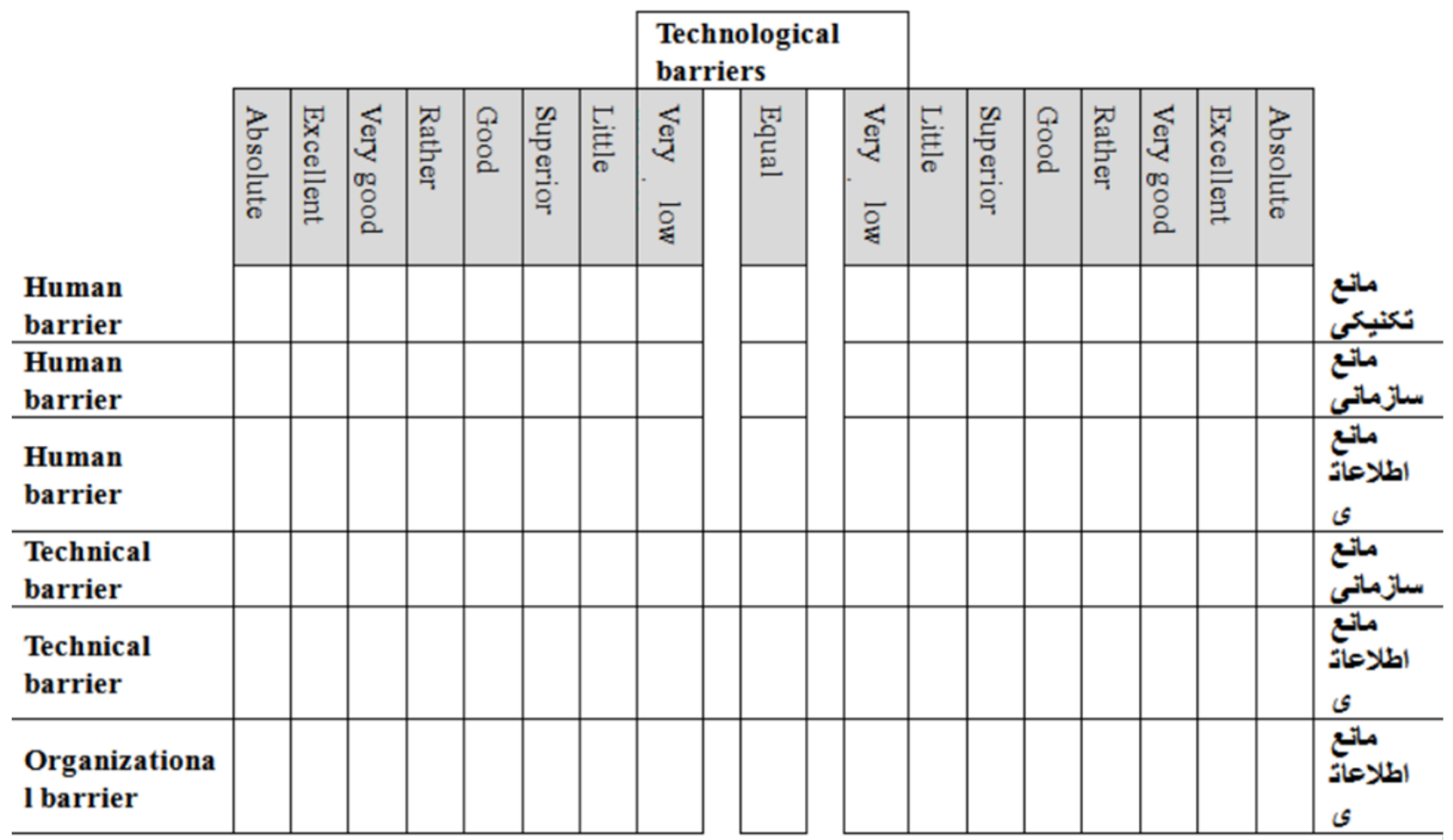

2. In recognition of technical barriers technology transfer, please compare barriers financial, legal, sanctions, infrastructure and complexity with each other. 


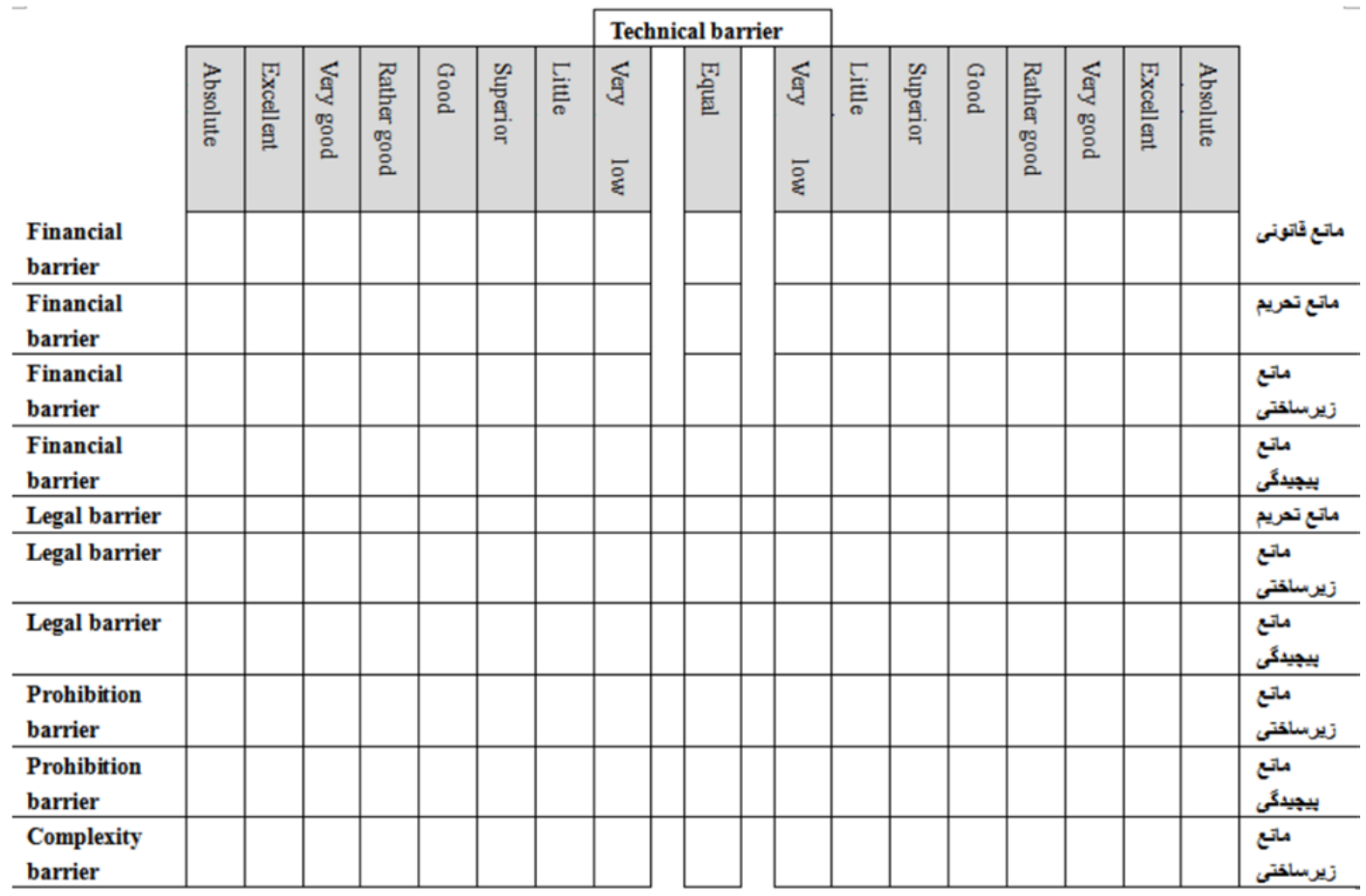

3. In recognition of the institutional barriers technology transfer, please barriers value, compare your support and instability.

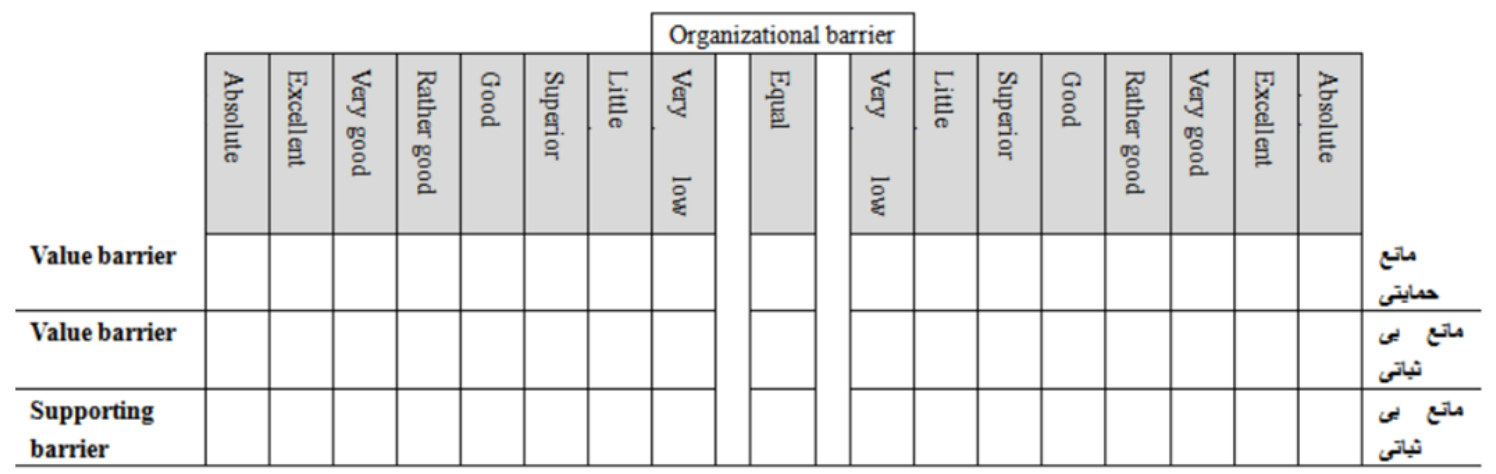

4. In recognition of the human barriers technology transfer, please barriers human skills, management skills, lack of innovation and lack of knowledge staff to compare your spirit.

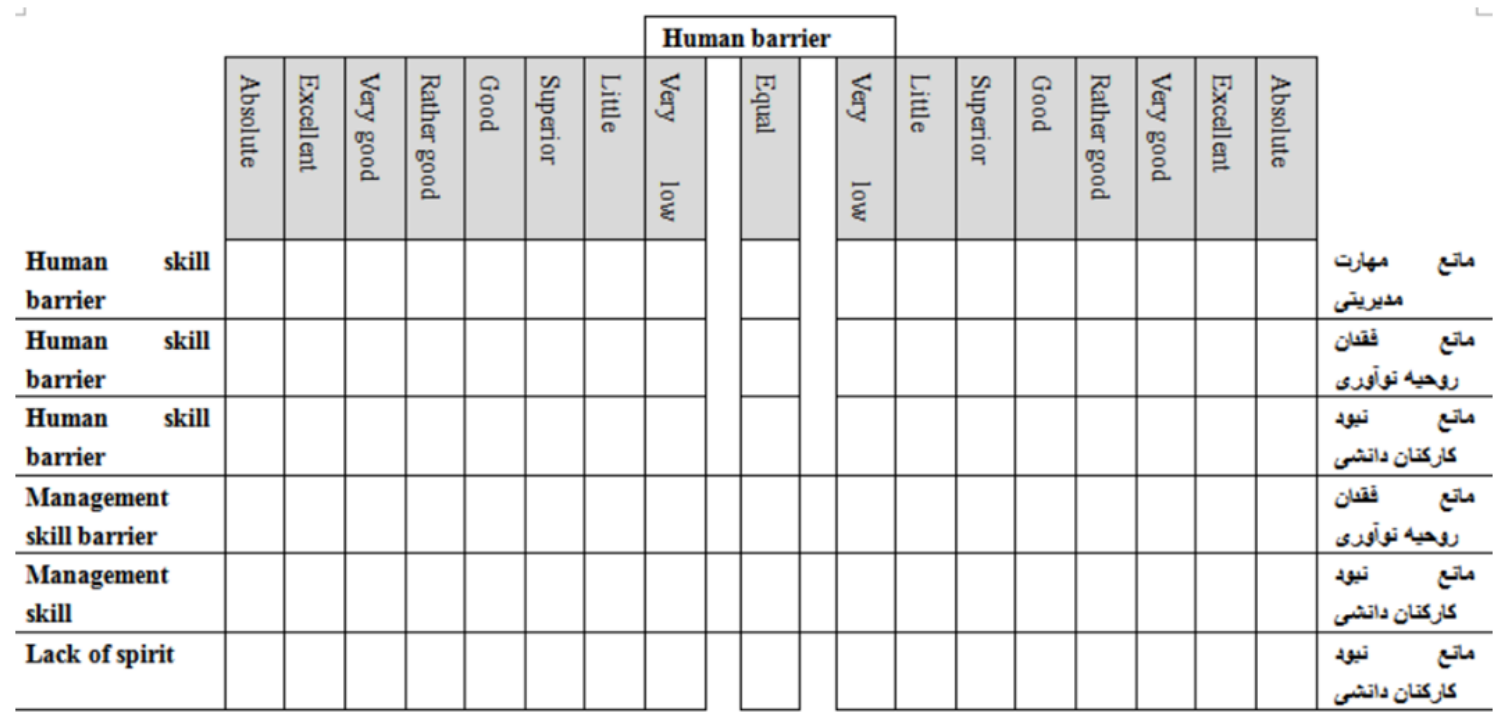


5. In line with identify barriers to technology transfer information, please communication barriers, costs, marketing inefficient and inaccurate to compare your choice.

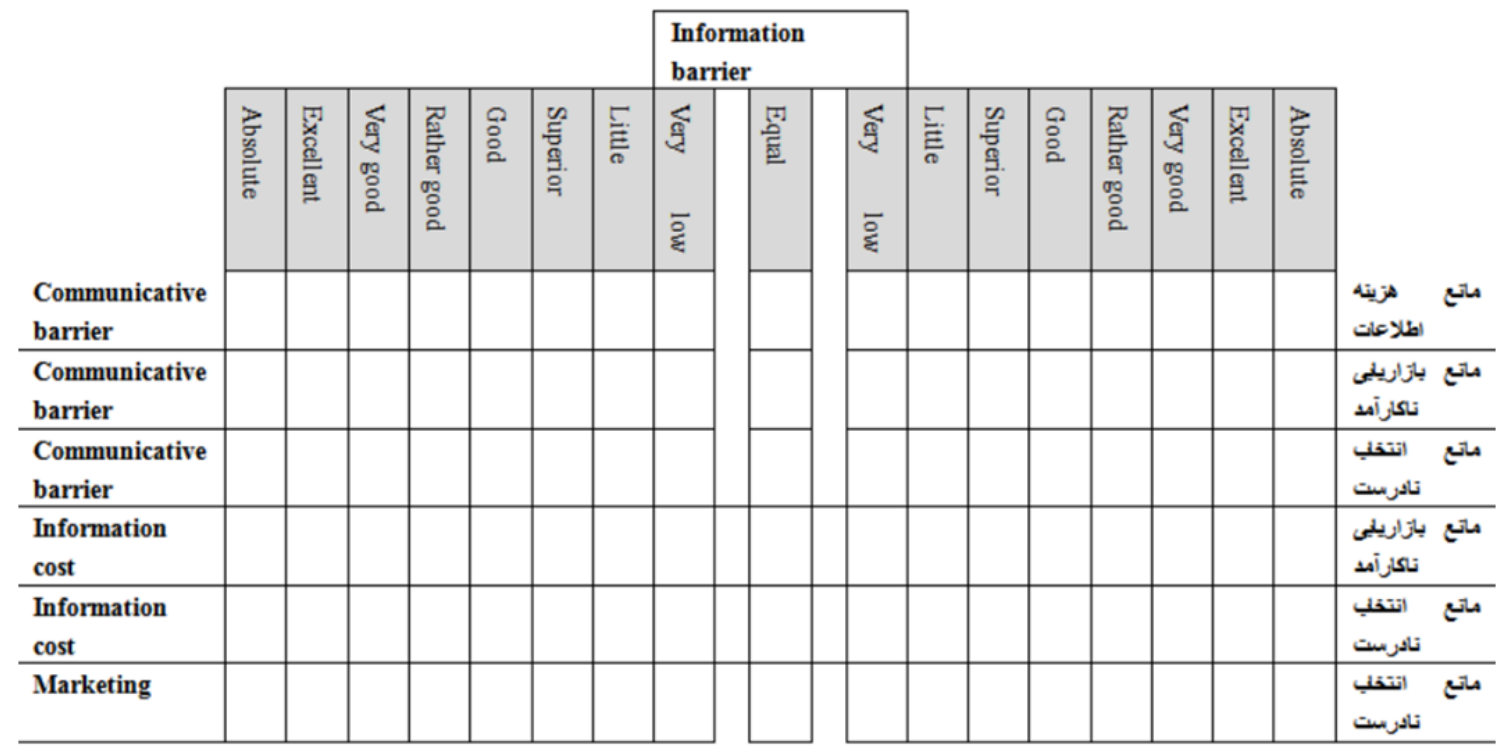

\section{Copyrights}

Copyright for this article is retained by the author(s), with first publication rights granted to the journal.

This is an open-access article distributed under the terms and conditions of the Creative Commons Attribution license (http://creativecommons.org/licenses/by/3.0/). 